\title{
Concentration Dependence of Active Potassium Transport in the Human Red Blood Cell in the Presence of Inhibitors
}

\author{
JoHN R. SACHS and Louis G. WeLT \\ From the Department of Medicine, University of North Carolina School of \\ Medicine, Chapel Hill, North Carolina 27514
}

\begin{abstract}
A B S T R A C T The active potassium influx in the human red blood cell is inhibited by strophanthidin, ethacrynic acid, and MK-870 (a new diuretic), and the degree of inhibition is greater at low concentrations of extracellular potassium than at high. In the case of ethacrynic acid, potassium appears to diminish the rate of combination of the drug with the transport system. The kinetic behavior of the active potassium influx in the presence of the inhibitors strophanthidin and ethacrynic acid is consistent with a model in which the binding of potassium at one of the potassium-sensitive sites in the transport system reduces the affinity of the system for the drug, and binding of a second potassium ion further reduces the affinity. It is not possible to distinguish between the sites on the basis of the studies presented here.
\end{abstract}

\section{INTRODUCTION}

The kinetic behavior of the active potassium influx in the human red blood cell is such that it suggests that potassium is simultaneously required at two external sites before transport occurs (1). In terms of the kinetic formulation previously presented, it is not possible to determine from the kinetic behavior of the system nor from the competitive effects of univalent cations whether the two sites are identical in their characteristics, or whether they possess properties by which they can be distinguished (2). We thought it of interest to

Dr. John R. Sachs' present address is the Department of Hematology, Division of Medicine, Walter Reed Army Institute of Research, Washington, D. C. Dr. Sachs performed this work during the term of an advanced research fellowship of the American Heart Association.

Received for publication 25 July 1967 and in revised form 16 November 1967. determine whether the behavior of the system in the presence of inhibitors is consistent with the two-site hypothesis. It also seemed possible that inhibitors might be found which would affect one of the sites and not the other, and therefore enable one to distignuish the sites by means of the kinetic behavior of the system in the presence of the inhibitor.

Cardiac glycosides and aglycones have been extensively utilized as inhibitors of active cation transport in the human red blood cell since the discovery of their transport-inhibiting effect by Schatzmann (3). Glynn (4) presented evidence that the presence of extracellular potassium competes with the effect of the drug. Hoffman (5) has shown that competition between extracellular potassium and the effect of the cardiotonic steroids appears to result from the prevention by potassium of the binding of the drug to the membrane sites at which it elicits its effect. It seemed possible that only one of the two potassium sites might be involved in the competition with the drug effect, and it therefore could be distinguished from the other.

Ethacrynic acid, a new diuretic (6), has been shown by Hoffman and Kregenow (7) to inhibit sodium outflux in red blood cells when this agent is superimposed on cardiac glycoside. They refer to this as Pump II (in contrast to Pump I which is defined by the inhibition induced by glycoside alone). This particular operational description is now known (8) not to be dependent on the sulfhydryl activity of ethacrynic acid. As will be evident. the studies reported here concern an effect of ethacrynic acid alone and is not to be confused with so-called Pump II. We have found that the drug inhibits the active potassium influx, and dem- 
onstrates competition with potassium. In the case of this drug, too, the competition with potassium appears to reflect inhibition by potassium of the binding of the drug to the site at which it exerts
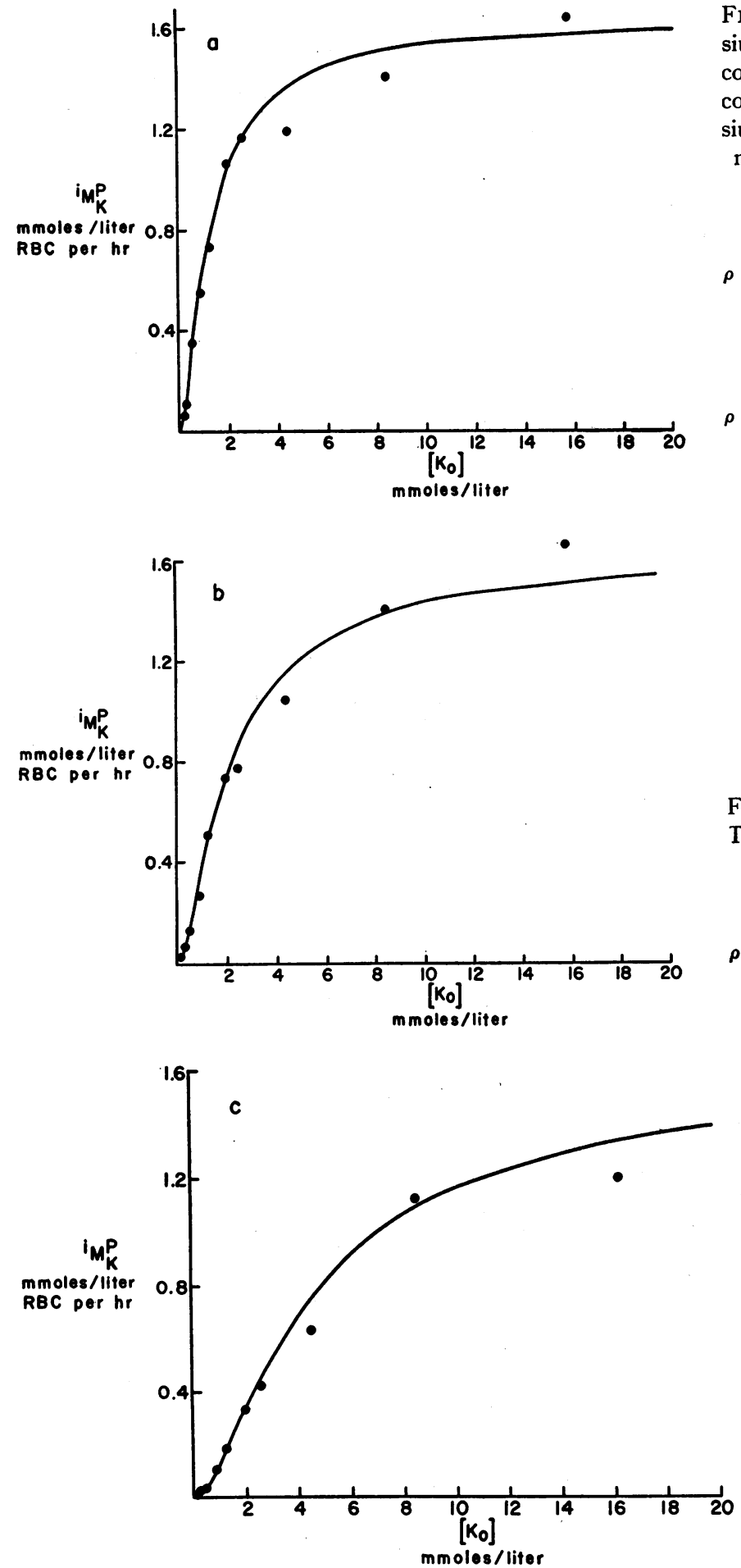

its effect. The kinetic behavior of the system in the presence of this inhibitor also seemed to offer the possibility of distinguishing between the two potassium sites.

FIGURE $1 a$ The relation between the active potassium influx ( ${ }^{i} \mathrm{M}_{K}{ }^{P}$ ) and the extracellular potassium concentration $\left(\left[\mathrm{K}_{0}\right]\right)$ in the presence of varying concentrations of strophanthidin. The active potassium influx was calculated as described in the text. $\mathrm{n}$, each case, the value of ${ }^{i} \mathrm{M}_{\mathrm{K}} \mathrm{L}$ is given by

$$
{ }^{\mathrm{i}} \mathrm{M}_{\mathrm{K}}^{\mathrm{L}} \text { (mmoles/liter) }=\frac{1.12}{1+\frac{11.5}{\mathrm{~J}}} \text {. }
$$

$\rho=0.991$.

$1 a$, control, no strophanthidin. The curve is:

$$
{ }^{i} \mathrm{M}_{\mathrm{K}}{ }^{\mathrm{P}}=\frac{1.67}{1+0.72 \frac{1}{\left[\mathrm{~K}_{\mathrm{o}}\right]}+0.87 \frac{1}{\left[\mathrm{~K}_{\mathrm{o}}\right]^{2}}} \text {. }
$$

$\rho$ (index of curvilinear correlation) $=0.989$.

Figure $1 b$ Strophanthidin, $2 \times 10^{-8}$ mole/liter. The curve is:

$\rho=0.989$.

$$
{ }^{i} \mathrm{M}_{\mathrm{K}} \mathrm{P}=\frac{1.67}{1+0.72 \frac{1}{\left[\mathrm{~K}_{\mathrm{o}}\right]}+2.00 \frac{1}{\left[\mathrm{~K}_{\mathrm{o}}\right]^{2}}} .
$$

FIGURE $1 c$ Strophanthidin, $10^{-7}$ mole/liter. The curve is:

$$
{ }^{\mathrm{i}} \mathrm{M}_{\mathrm{K}}^{\mathrm{P}}=\frac{1.67}{1+3.33 \frac{1}{\left[\mathrm{~K}_{\mathrm{o}}\right]}+8.67 \frac{1 .}{\left[\mathrm{K}_{\mathrm{o}}\right]^{2}}}
$$

$\rho=0.989$. The measurements were made in solutions containing (mmoles/liter): gylcyl glycine, $33 \rightarrow 27 ; \mathrm{Mg}^{++}, 14 \rightarrow 5 ; \mathrm{K}^{+}, 0.2 \rightarrow 16 ; \mathrm{Na}^{+}$, $129 ; \mathrm{Cl}^{-}, 143 ; \mathrm{PO}_{4}, 1.2$; glucose, 9; and ethanol, $1 \% \mathrm{v} / \mathrm{v}$. As the concentration of potassium increases, the concentrations of gylcyl glycine and magnesium decrease. 
MK-870, a new diuretic consisting of a substituted pyrazine ring to which a guanidine grouping is attached, also behaves kinetically in a manner similar to that of the cardiotonic steroids and ethacrynic acid. The drug is, however, a weak inhibitor of the active transport process at concentrations which can be attained, and the mechanism of inhibition is not clear. ${ }^{1}$

\section{METHODS}

The solutions used, the manipulation of the cells, and the methods employed for determination of the unidirectional fluxes were as previously described (1). In the experiments employing ethacrynic acid and MK-870, the active potassium influx $\left({ }^{1} \mathrm{M}_{\mathbf{R}}{ }^{\mathrm{P}}\right)$ was taken as the difference between the potassium influx $\left({ }^{1} \mathbf{M}_{\mathbf{K}}{ }^{\mathbf{T}}\right)$ in cells whose energy stores had, after a period of starvation, been restored by exposure to $3 \mathrm{~mm}$ adenine, $10 \mathrm{~mm}$ inosine, and $9 \mathrm{~mm}$ glucose, and the potassium influx $\left({ }^{1} \mathbf{M}_{\mathbf{K}}{ }^{\mathbf{L}}\right)$ in starved cells to which strophanthidin at a final concentration of $10^{-4}$ mole/liter had been added. Neither ethacrynic acid nor MK-870 at the concentrations used caused any increase

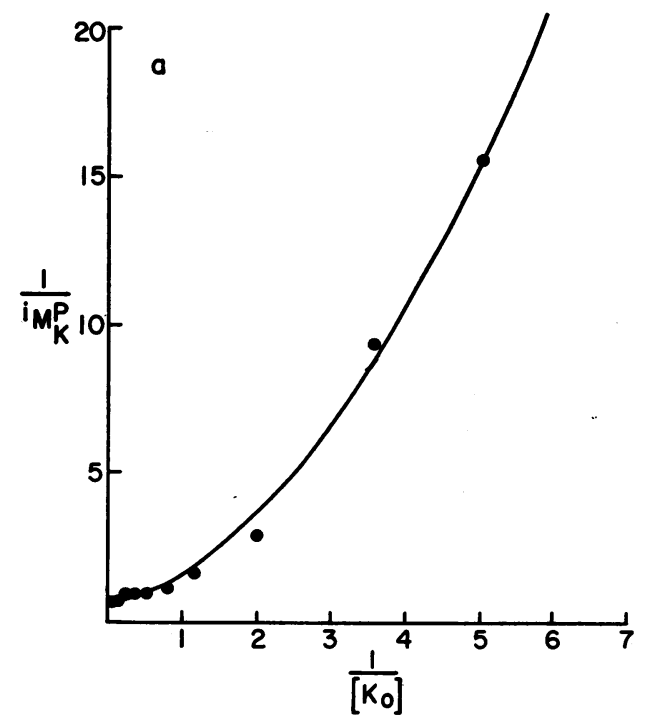

FIGURE $2 a$ The reciprocal of the active potassium influx $\left(\frac{1}{{ }^{i} \mathbf{M}_{\mathbf{K}} \mathbf{P}}\right)$ vs. the reciprocal of the extracellular potassium concentration $\left(\frac{1}{\left[\mathrm{~K}_{0}\right]}\right)$. The data are from the same experiment as are the data plotted in Fig. 1. 2a, control, no strophanthidin. The curve is:

$$
\frac{1}{{ }^{\mathrm{i}} \mathrm{M}_{\mathrm{K}}{ }^{\mathrm{P}}}=\frac{1}{1.67}+\frac{0.72}{1.67} \frac{1}{\left[\mathrm{~K}_{\mathrm{o}}\right]}+\frac{0.87}{1.67} \frac{1}{\left[\mathrm{~K}_{\mathrm{o}}\right]^{2}} .
$$

$\rho=0.997$.

1 Both of these agents, ethacrynic acid and $\mathrm{Mk}-870$, were kindly supplied in pure form by Merck, Sharp and Dohme Research Laboratories, West Point, Pa.

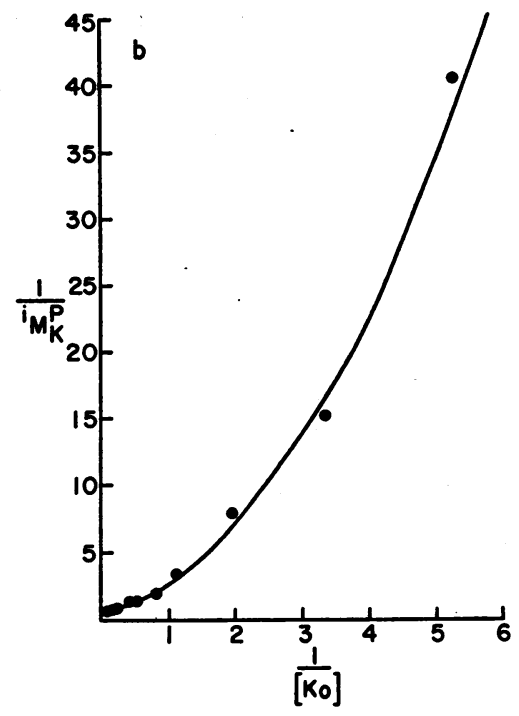

FIGURE $2 b$ Strophanthidin, $2 \times 10^{-8}$ mole/liter. The curve is:

$$
\frac{1}{{ }^{i} \mathrm{M}_{\mathrm{K}}{ }^{\mathrm{P}}}=\frac{1}{1.67}+\frac{1.43}{1.67} \frac{1}{\left[\mathrm{~K}_{\mathrm{o}}\right]}+\frac{2.00}{1.67} \frac{1}{\left[\mathrm{~K}_{\mathrm{o}}\right]^{2}} .
$$

$\rho=0.997$.

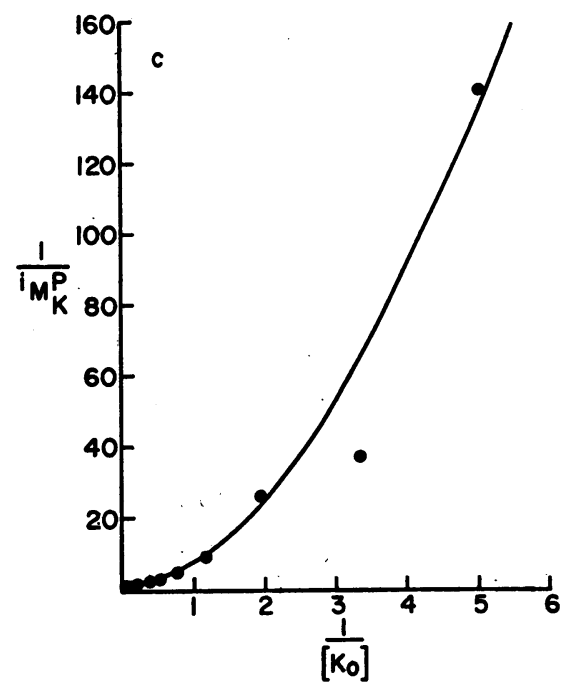

FIGURE $2 c$ Strophanthidin, $10^{-7}$ mole/liter. The curve is:

$$
\frac{1}{{ }^{\mathrm{i}} \mathrm{M}_{\mathrm{K}}^{\mathrm{P}}}=\frac{1}{1.67}+\frac{3.33}{1.67} \frac{1}{\left[\mathrm{~K}_{\mathrm{o}}\right]}+\frac{8.67}{1.67} \frac{1}{\left[\mathrm{~K}_{\mathrm{o}}\right]^{2}} \text {. }
$$

$\rho=0.973$.

in the passive potassium influx $\left({ }^{1} \mathrm{M}_{\mathrm{K}}{ }^{\mathrm{L}}\right)$. In the experiments in which the effect of strophanthidin was investigated, the active potassium influx was defined as the difference between the potassium influx in the absence of strophanthidin (or in the presence of a low strophanthidin concentration) and the potassium influx in the pres- 
ence of a concentration of strophanthidin which produces maximal inhibition $\left(10^{-4}\right.$ mole/liter $)$. Since strophanthidin does not completely inhibit the active potassium influx even at maximal concentrations, it seemed reasonable to consider as the base line only that proportion of the influx that is sensitive to strophanthidin.

Ethacrynic acid was added to the appropriate flasks as an ethanol solution, and MK-870 was added without the use of a carrier. Cellular ATP concentrations were measured as previously described (9). All experiments were performed three times with similar results.

Theoretical calculations. The active potassium transport system in the human red blood cell can be adequately described by a model of the form [1] :

$$
\begin{aligned}
& X+\mathrm{K}_{\mathrm{o}} \stackrel{k_{1}}{\rightleftharpoons k_{-1}} X \mathrm{~K} \\
& X \mathrm{~K}+\mathrm{K}_{\mathrm{o}} \underset{k_{-2}}{\stackrel{k_{2}}{\rightleftharpoons}} X 2 \mathrm{~K} \\
& X 2 \mathrm{~K} \stackrel{k_{3}}{\longrightarrow} X \mathrm{~K}+\mathrm{K}_{\mathrm{i}}
\end{aligned}
$$

TABLE I

Effect of Cysteine on the Inhibition of the Active Potassium Influx ( ${ }^{\mathrm{i}} \mathrm{M}_{\mathrm{K}}{ }^{\mathrm{P}}$ ) by Ethacrynic Acid

\begin{tabular}{cccc}
\hline & \multicolumn{3}{c}{${ }^{\mathrm{i} \mathrm{M}_{\mathrm{K}}^{\mathrm{P}}}$} \\
\cline { 2 - 4 } Solution & Subject 1 & Subject 2 & Subject 3 \\
\hline $\begin{array}{c}\text { mmoles/liter } R B C \text { per } h r \\
\text { Cysteine, } 10 \text { mmoles/liter } \\
\quad \text { Ethacrynic acid, } \\
\quad 8 \times 10^{-4} \text { mole/liter }\end{array}$ & 1.20 & 0.90 & 1.17 \\
$\quad$ No ethacrynic acid & 1.16 & 0.84 & 1.08 \\
$\begin{array}{c}\text { No cysteine } \\
\text { Ethacrynic acid, } \\
\quad 8 \times 10^{-4} \text { mole/liter }\end{array}$ & 0.17 & 0.15 & 0.16 \\
No ethacrynic acid & 0.92 & 0.88 & 0.99 \\
\hline
\end{tabular}

Solution in which the measurements were made contained (mmoles/liter): glycyl glycine, $28 ; \mathrm{Mg}^{++}, 5 ; \mathrm{Na}^{+}, 144$; $\mathrm{K}^{+}, 2.2 ; \mathrm{Cl}^{-}, 144 ; \mathrm{PO}_{4}, 1.2 ;$ glucose, 9 ; and ethanol $2 \% \mathrm{v} / \mathrm{v}$.

\begin{tabular}{|c|c|c|c|c|}
\hline \multirow[b]{2}{*}{ Preincubation solution } & \multirow[b]{2}{*}{ Influx solution } & \multicolumn{3}{|c|}{${ }^{\mathrm{i}} \mathbf{M}_{\mathrm{K}} \mathbf{P}$} \\
\hline & & Subject 1 & Subject 2 & Subject 3 \\
\hline & & \multicolumn{3}{|c|}{ mmoles/liter $R B C$ per $h r$} \\
\hline Ethacrynic acid, $10^{-3}$ mole/liter & Cysteine, 10 mmoles/liter & 0.25 & 0.33 & 0.23 \\
\hline Ethacrynic acid, $10^{-3}$ mole/liter & No cysteine & 0.20 & 0.25 & 0.23 \\
\hline No ethacrynic acid & Cysteine, 10 mmoles/liter & 1.16 & 1.05 & 2.16 \\
\hline No ethacrynic acid & No cysteine & 1.34 & 0.75 & 1.89 \\
\hline
\end{tabular}

TABLE II

Effect of Preincubation with Ethacrynic Acid on the Active Potassium Influx $\left({ }^{\mathrm{i}} \mathrm{M}_{\mathrm{K}}{ }^{\mathrm{P}}\right.$ )

Cells were preincubated for $1 \mathrm{hr}$ only in the presence or absence of $10^{-3} \mathrm{M}$ ethacrynic acid, and then the cells washed and the active potassium influx determined in the presence or absence of cysteine.

Solution in which the measurements were made was of the same composition as that described in Table I.

TABLE III

\begin{tabular}{|c|c|c|c|}
\hline \multirow[b]{3}{*}{ Preincubation solution } & \multicolumn{3}{|c|}{${ }^{\mathrm{i}} k_{\mathrm{K}} \mathrm{P}$ determined in cells exposed to ethacrynic acid } \\
\hline & \multicolumn{3}{|c|}{${ }^{\mathrm{i}} k_{\mathrm{K}} \mathrm{P}$ determined in cells not exposed to ethacrynic acid } \\
\hline & Subject 1 & Subject 2 & Subject 3 \\
\hline $\mathrm{Na}^{+}, 144$ mmoles/liter & $0.34\left(\frac{0.26}{0.76}\right)$ & $.37\left(\frac{0.31}{0.84}\right)$ & $0.46\left(\frac{0.26}{0.57}\right)$ \\
\hline $\mathrm{K}^{+}, 144$ mmoles/liter & $0.68\left(\begin{array}{l}0.39 \\
0.57\end{array}\right)$ & $.61\left(\frac{0.40}{0.66}\right)$ & $0.71\left(\frac{0.32}{0.45}\right)$ \\
\hline
\end{tabular}

Protection by Potassium against the Inhibition of Ethacrynic Acid of ${ }^{\mathrm{i}} \mathrm{k}_{\mathrm{K}}{ }^{\mathrm{P}}$, the "Rate Constant" of the Active Potassium Influx

The ratio of the "rate constant" of active potassium influx determined in cells preincubated in the presence of ethacrynic acid to the "rate constant" of active potassium influx determined in cells preincubated in the absence of ethacrynic acid is presented. The experimental procedure is described in the text.

Solution in which the measurements were made was of the same composition as that described in Table I, except that $\mathrm{K}^{+}=$ca. $0.35 \mathrm{mmole} /$ liter. 
TABLE IV

Effect of Extracellular Potassium on the Inhibition of the Active Potassium Influx by Ethacrynic Acid

\begin{tabular}{ccc}
\hline & \multicolumn{2}{c}{$\begin{array}{c}\text { Fraction of active potassium influx } \\
\text { not inhibited }\end{array}$} \\
\cline { 2 - 3 } $\begin{array}{c}\text { Ethacrynic acid } \\
\text { concentration }\end{array}$ & $\begin{array}{c}\mathrm{K}_{\mathrm{o}}=0.23 \\
\text { mmoles/liter }\end{array}$ & $\begin{array}{c}\mathrm{K}_{\mathrm{o}}=8.4 \\
\text { mmoles/liter }\end{array}$ \\
\hline $3 \times 10^{-5} \mathrm{~mole} / \mathrm{liter}$ & $1.02(0.91-1.07)$ & $1.10(1.05-1.16)$ \\
$9 \times 10^{-5} \mathrm{~mole} / \mathrm{liter}$ & $0.85(0.73-0.93)$ & $1.18(1.11-1.28)$ \\
$5 \times 10^{-4} \mathrm{~mole} / \mathrm{liter}$ & $0.14(0.12-0.17)$ & $0.53(0.49-0.57)$ \\
$8 \times 10^{-4} \mathrm{~mole} / \mathrm{liter}$ & $0.08(0.04-0.12)$ & $0.31(0.28-0.36)$ \\
\hline
\end{tabular}

The value of the active potassium influx at each concentration of ethacrynic acid was divided by the value of the active potassium influx in the absence of ethacrynic acid; the mean and range of three determinations are given. The solution in which the measurements were made was essentially the same as that described in Table I.

where $X$ is a component or interrelated components of the active transport system, present in limited quantities, and requiring the presence of two potassium ions simultaneously before transport occurs; $K_{0}$ is extracellular potassium; and $K_{1}$ is intracellular potassium. ${ }^{1} \mathrm{M}_{\mathbf{K}}{ }^{\mathrm{P}}$ (the active potassium influx) $=k_{3}[X 2 \mathrm{~K}]$, and $k_{3}$ is assumed to be so much less than the other rate constants that reactions 1 and 2 are at equilibrium. Then the relation between the active potassium influx and the extracellular potassium concentration is :

$$
{ }^{i} \mathrm{M}_{\mathrm{K}} \mathrm{P}=1+\frac{a}{\frac{b}{\left[\mathrm{~K}_{\mathrm{o}}\right]}+\frac{c}{\left[\mathrm{~K}_{\mathrm{o}}\right]^{2}}},
$$

or :

$$
\frac{1}{\mathrm{i}_{\mathrm{K}} \mathrm{P}}=\frac{1}{a}+\frac{b}{a} \frac{1}{\left[\mathrm{~K}_{\mathrm{o}}\right]}+\frac{c}{a} \frac{1}{\left[\mathrm{~K}_{\mathrm{o}}\right]^{2}}
$$

where $a, b$, and $c$ are constants. The results obtained in the presence of inhibitors have been fitted to equations of the form of equation 5. From the response of the constants to the presence of inhibitors, some inferences have been drawn about the mode of interaction of potassium, inhibitor, and the cation transport system.

\section{RESULTS}

Effect of strophanthidin. Fig. 1 represents the relation between the active (strophanthidin-sensitive) potassium influx and the extracellular potassium concentration in the absence of strophanthidin and in the presence of two low concentrations of strophanthidin; Fig. 2 is a plot of the reciprocal of the active potassium influx vs. the reciprocal of the extracellular potassium concentration from the data from the same experiment. It can be seen that at neither concentration of strophanthidin was the value of the constant term increased; at both concentrations the coefficient of the term in $1 /\left[K_{0}\right]$ was increased, and at both concentrations the coefficient of the term in $1 /\left[\mathrm{K}_{0}\right]^{2}$ was increased to a greater extent.

Effect of ethacrynic acid on the active potassium influx. Table I lists the results of three experiments in which active potassium influx was measured in solutions which were identical except for the presence or absence of ethacrynic acid and of cysteine. It can be seen that ethacrynic acid markedly inhibits the active potassium influx, but that addition of cysteine to the solution containing ethacrynic acid before the addition of the cells eliminates the ethacrynic acid effect. Table II represents the results of an experiment in which cells were preincubated in the presence or absence of ethacrynic acid washed, and the active potassium influx then measured in the presence or absence of cysteine. It appears that the ethacrynic acid effect cannot be washed off, and that the effect, once

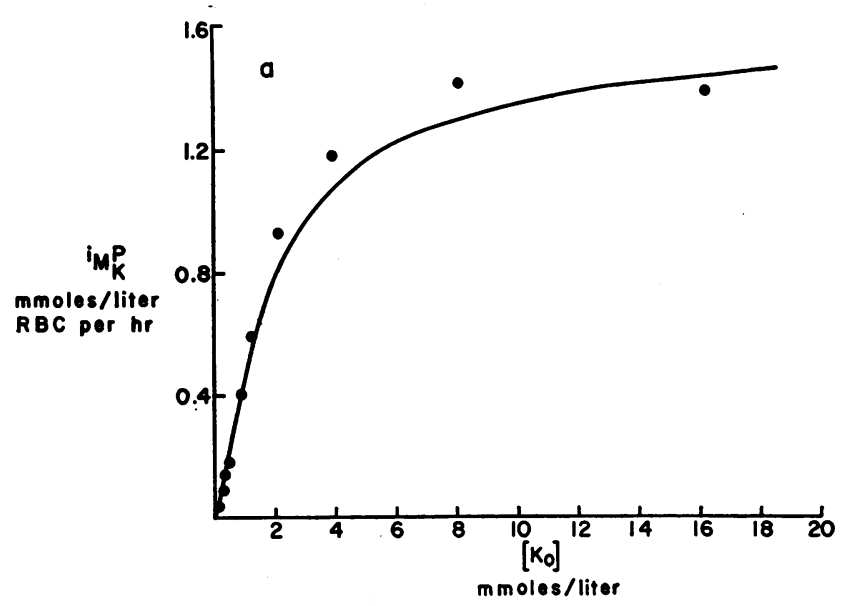

Figure $3 a$ The relation between the active potassium influx ( ${ }^{i} \mathbf{M}_{\mathbf{K}}{ }^{\mathbf{P}}$ ) and the extracellular potassium concentration $\left(\left[\mathrm{K}_{\mathbf{0}}\right]\right)$ in the presence and absence of ethacrynic acid. $3 a$ control, no ethacrynic acid. The curve is:

$$
{ }^{i} \mathrm{M}_{K} \mathrm{P}=\frac{1.59}{1+1.63 \frac{1}{\left[\mathrm{~K}_{\mathrm{o}}\right]}+0.84 \frac{1}{\left[\mathrm{~K}_{\mathrm{o}}\right]^{2}}} .
$$

$\rho=0.993$. The value of ${ }^{i} M_{K}{ }^{L}$ is given by

${ }^{i} M_{K} L=-0.00073+0.0268\left[K_{0}\right], r=0.999$.

The Concentration Dependence of Potassium Transport in the Red Blood Cell 


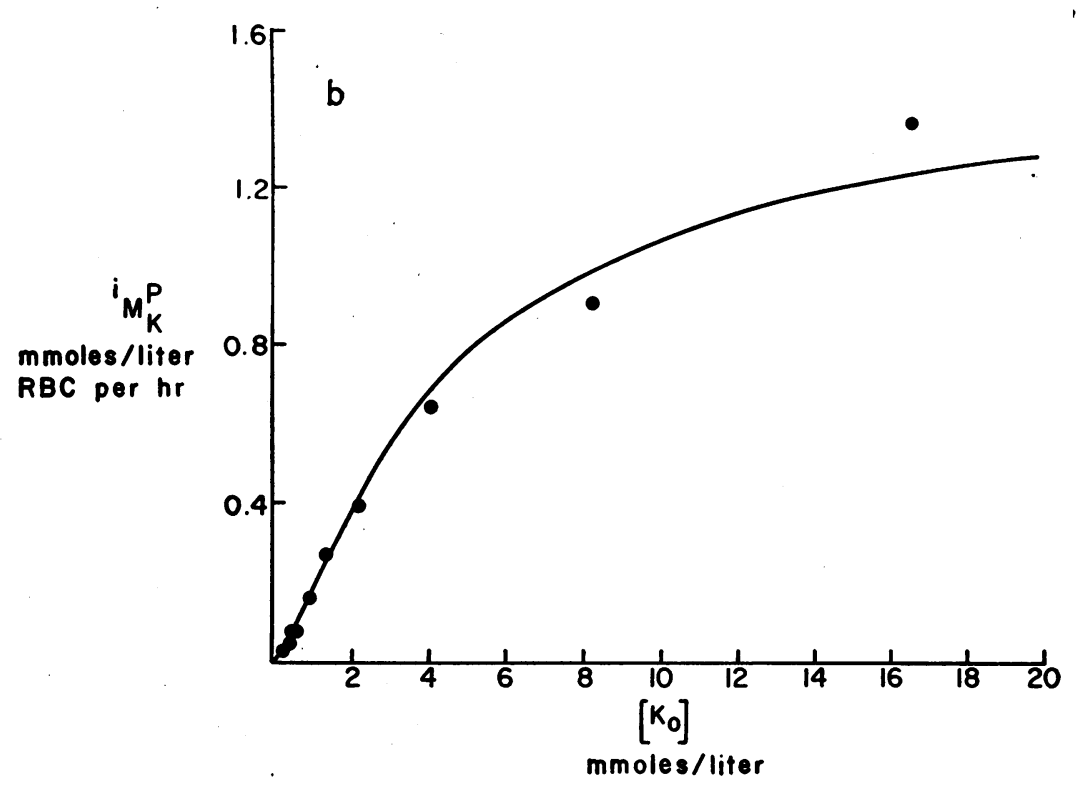

FIGURE $3 b$ Ethacrynic acid, $3 \times 10^{-4}$ mole/liter. The curve is:

$$
{ }^{i} \mathrm{M}_{\mathrm{K}} \mathrm{P}=\frac{1.59}{1+4.65 \frac{1}{\left[\mathrm{~K}_{0}\right]}+3.24 \frac{1}{\left[\mathrm{~K}_{0}\right]^{2}} .}
$$

$\rho=0.991$. The value of ${ }^{i} \mathrm{M}_{K}{ }^{\mathrm{L}}$ is given by ${ }^{\mathrm{i}} \mathrm{M}_{\mathrm{K}} \mathrm{L}=-0.0017+0.0454\left[\mathrm{~K}_{0}\right]$, $r=0.999$. The solutions in which the measurements were made were of the same composition as those described in Fig. 1.

established, cannot be reversed by concentrations of cysteine which will neutralize $8 \times 10^{-4} \mathrm{~mole} /$ liter ethacrynic acid. The effect of ethacrynic acid, once established, seems to be essentially irreversible.

In Table III are presented the results of an experiment designed to determine whether the interaction of ethacrynic acid with the active transport system is inhibited by potassium. Cells were incubated for $1 \mathrm{hr}$ at $37^{\circ} \mathrm{C}$ in either buffered sodium chloride or potassium chloride solutions, and in either the presence or absence of ethacrynic acid at a concentration of $5 \times 10^{-6} \mathrm{~mole} / \mathrm{liter}$. The cells were then removed, washed in sodium chloride solution, and the "rate constant" of the active potassium influx, ${ }^{1} k_{\mathrm{K}}{ }^{\mathrm{P}}$, determined. $\left({ }^{1} k_{\mathrm{K}}{ }^{\mathrm{P}}\right.$ is the number which, when multiplied by the extracellular potassium concentration, will yield the value of the active potassium influx.) The value of ${ }^{1} k_{\mathrm{K}}{ }^{\mathrm{P}}$, determined in cells preincubated in sodium chloride solution in the presence of ethacrynic acid, was divided by the value of ${ }^{1} k_{\mathbf{K}}{ }^{\mathrm{P}}$ determined in cells preincubated in sodium chloride solution in the absence of ethacrynic acid, to yield a measure of the fraction of the influx which was not inhibited by ethacrynic acid. Similar calculations were performed for the determinations in the cells preincubated in the potassium chloride solution. It can be seen that the fraction remaining uninhibited by ethacrynic acid is greater in the cells exposed to ethacrynic acid in the presence of high concentrations of potassium. Potassium appears to interfere with the binding of ethacrynic acid to the transport system.

Table IV presents the results of experiments in which the active potassium influx was measured at two potassium concentrations and at varying concentrations of ethacrynic acid. It is seen that the fraction which remains uninhibited at any ethacrynic acid concentration is less at the low potassium concentration than at the high.

Fig. 3 represents the relation between the active potassium influx and the extracellular potassium concentration in the presence and in the absence of $3 \times 10^{-4} \mathrm{M}$ ethacrynic acid. In Fig. 4, the reciprocal of the active potassium influx is plotted against the reciprocal of the extracellular potassium concentration; the data are from the same experiment 


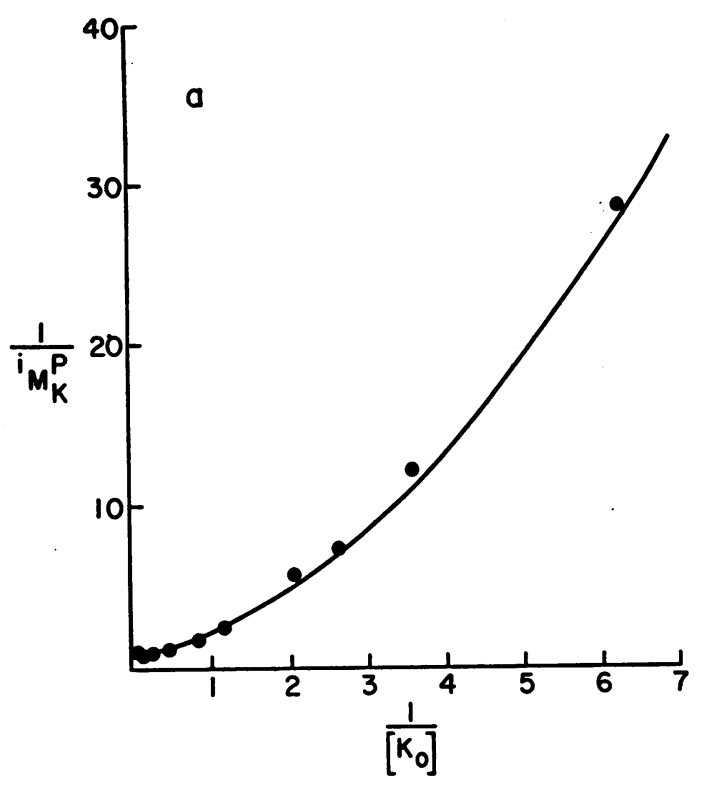

FIgURE $4 a$ The reciprocal of the active potassium influx $\left(\frac{1}{{ }^{i} M_{K}{ }^{p}}\right)$ vs. the reciprocal of the extracellular potassium concentration $\left(\frac{1}{\left[\mathrm{~K}_{\mathrm{o}}\right]}\right)$. The data are from the same experiment as are the data plotted in Fig. 3. 4a, control, no ethacrynic acid. The curve is:

$$
\frac{1}{\mathrm{i}_{\mathrm{M}} \mathrm{P}^{\mathrm{P}}}=\frac{1}{1.59}+\frac{1.63}{1.59} \frac{1}{\left[\mathrm{~K}_{\mathrm{o}}\right]}+\frac{0.84}{1.59} \frac{1}{\left[\mathrm{~K}_{\mathrm{o}}\right]^{2}} .
$$

$\rho=0.998$.

as those plotted in Fig. 3. Again, the value of the constant term was not increased in the presence of ethacrynic acid; the coefficient of the term in $1 /\left[K_{0}\right]$ was increased, and the coefficient of the term in $1 /\left[\mathrm{K}_{0}\right]^{2}$ was increased to a greater extent.

In order to be certain that the inhibitor is not exerting its effect by interfering with cell metabolism, an experiment was performed in which the cells were incubated in the presence of ethacrynic acid under circumstances similar to those under which the potassium influx was measured. Table $\mathrm{V}$ represents the results of three such experiments; it is seen that incubation in the presence of ethacrynic acid does not lead to depletion of cellular ATP.

Effect of $M K-870$ on the active potassium influx. Fig. 5 represents the relation between the active potassium influx and the extracellular potassium concentration in the presence and in the absence of MK-870; Fig. 6 depicts the relation between the reciprocal of the active potassium influx and the reciprocal of the extracellular potas-

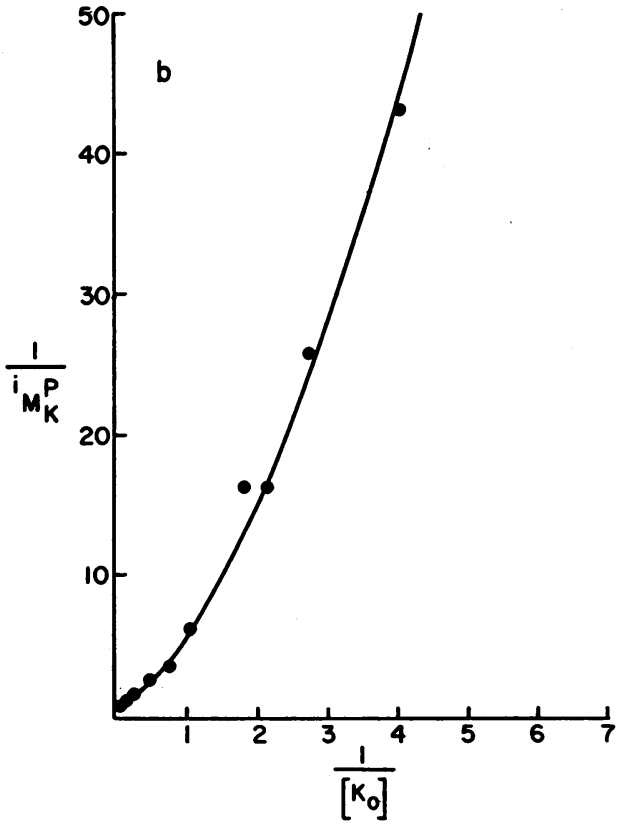

Figure $4 b$ Ethacrynic acid, $3 \times 10^{-4}$ mole/liter. The curve is:

$$
\frac{1}{\mathrm{i}_{\mathrm{K}}{ }^{\mathrm{P}}}=\frac{1}{1.59}+\frac{4.65}{1.59} \frac{1}{\left[\mathrm{~K}_{\mathrm{o}}\right]}+\frac{3.24}{1.59} \frac{1}{\left[\mathrm{~K}_{\mathrm{o}}\right]^{2}} .
$$

$\rho=0.993$.

sium concentration of the data from the same experiment. The coefficients of the terms in $1 /\left[\mathrm{K}_{0}\right]$ and $1 /\left[\mathrm{K}_{0}\right]^{2}$ are both increased by about the same factor, and the value of the constant term remains unchanged.

\section{DISCUSSION}

In terms of the model presented in the theoretical section, the inhibitors might react with the transport system in the form $X, X \mathrm{~K}$, or $X 2 \mathrm{~K}$. Hoffman has shown (5) that the interaction of the cardiotonic steroids with the transport sysem is inhibited

\section{TABLE V}

Red Blood Cell ATP Concentrations after Incubation for $1 \frac{1}{2} \mathrm{Hr}$ in the Presence of $8 \times 10^{-4} \mathrm{M}$ Ethacrynic Acid

\begin{tabular}{ccc}
\hline & \multicolumn{2}{c}{ ATP } \\
\cline { 2 - 3 } Subject & Control & Ethacrynic Acid \\
\hline & \multicolumn{2}{c}{ mmoles/liter $R B C$} \\
2 & 1.14 & 1.36 \\
3 & 1.13 & 1.18 \\
& 0.91 & 1.05 \\
\hline
\end{tabular}

Solution in which the cells were incubated was the same as that solution described in Table I. 


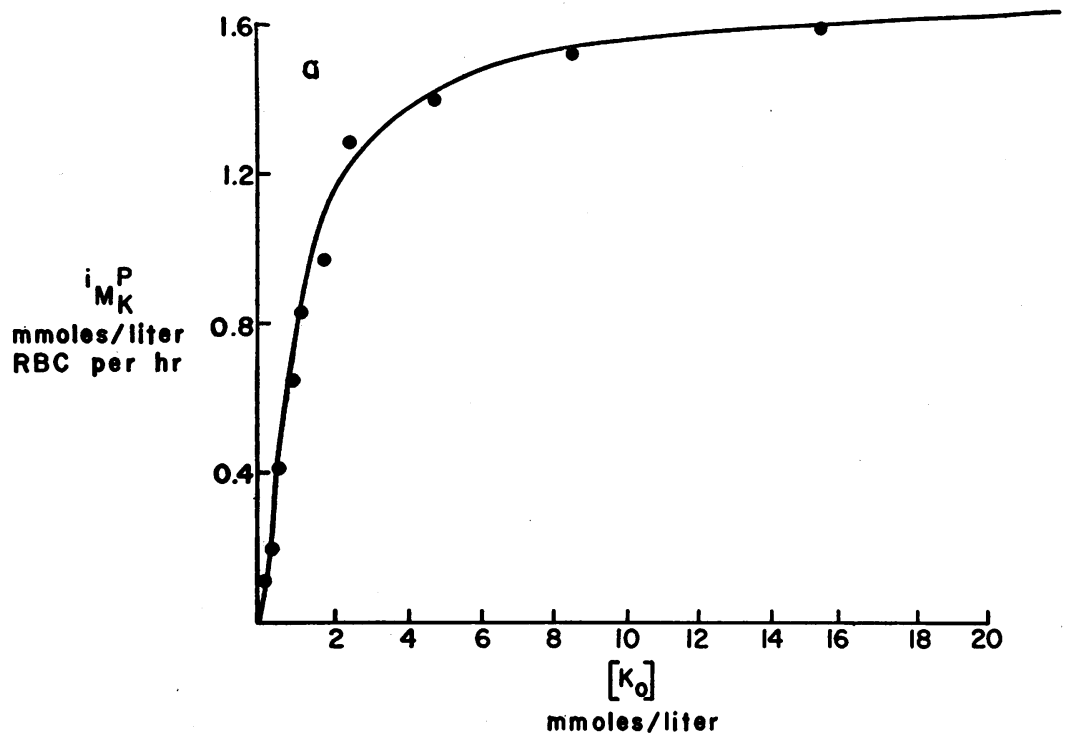

FIGURE $5 a$ The relation between the active potassium influx ( ${ }^{i} M_{K}{ }^{P}$ ) and the extracellular potassium concentration $\left(\left[\mathrm{K}_{\mathrm{o}}\right]\right.$ ) in the presence and absence of MK-870. The value of ${ }^{i} \mathrm{M}_{\mathrm{K}}{ }^{\mathrm{L}}$ in each case is given by ${ }^{i} \mathrm{M}_{\mathrm{K}}{ }^{\mathrm{L}}=0.00114+0.0251\left[\mathrm{~K}_{0}\right], r=0.994$. $5 a$, control, no MK-870. The curve is:

$\rho=0.993$.

$$
{ }^{i} \mathrm{M}_{K^{P}}=\frac{1.69}{1+0.85 \frac{1}{\left[\mathrm{~K}_{\mathrm{o}}\right]}+0.27 \frac{1}{\left[\mathrm{~K}_{\mathrm{o}}\right]^{2}}} .
$$

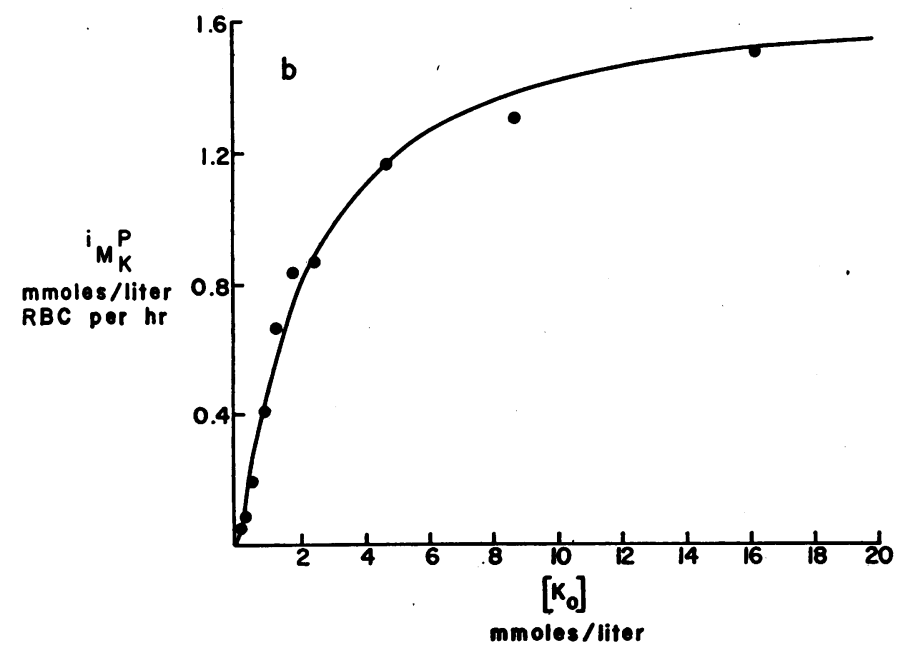

Figure 5 b MK-870, $10^{-3}$ mole/liter. The curve is:

$$
{ }^{i} \mathrm{M}_{K^{P}}=\frac{1.69}{1+1.98 \frac{1}{\left[\mathrm{~K}_{0}\right]}+0.66 \frac{1}{\left[\mathrm{~K}_{0}\right]^{2}}} .
$$

$\rho=0.993$. The solutions in which the measurements were made were of the same composition as those described in Fig. 1.

by extracellular potassium, and from the results presented here, the same condition seems to obtain in the case of ethacrynic acid; therefore, the rates of reaction of inhibitor with $X, X \mathrm{~K}$, and $X 2 \mathrm{~K}$ might be different. In the case of both drugs, the interaction of the inhibitor $(I)$ with the system seems to be irreversible. This may be represented

as :

$$
\begin{gathered}
X+I \stackrel{k^{{ }^{\prime}}}{\longrightarrow} X I \\
X \mathrm{~K}+I \stackrel{k^{{ }^{\prime}}}{\longrightarrow} X \mathrm{KI} I \\
X 2 \mathrm{~K}+I \stackrel{{k_{3}}^{\prime}}{\longrightarrow} X 2 \mathrm{~K} I .
\end{gathered}
$$




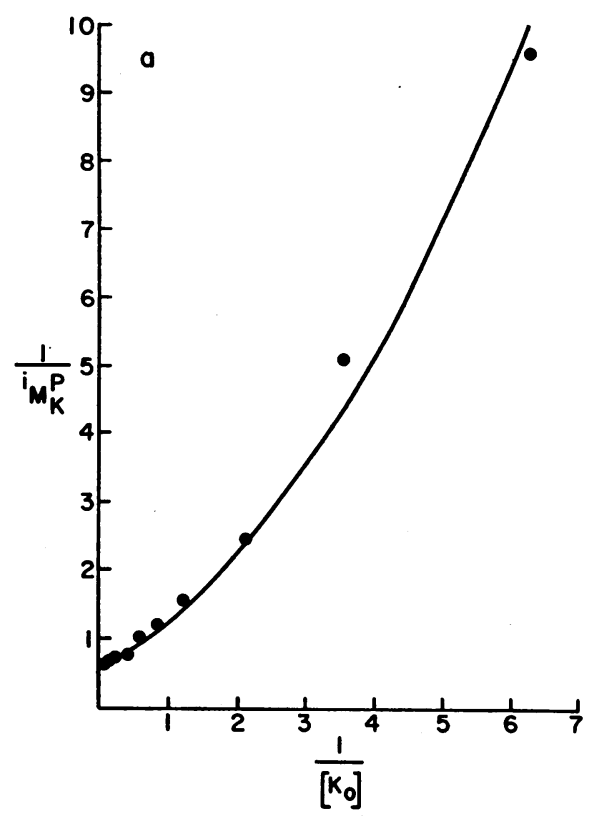

Figure $6 a$ The reciprocal of the active potassium influx $\left(\frac{1}{{ }^{i} M_{K^{P}}}\right)$ vs. the reciprocal of the extracellular potassium concentration $\left(\frac{1}{\left[\mathrm{~K}_{0}\right]}\right)$. The data are from the same experiment as are the data plotted in Fig. 5. $6 a$, control, no MK-870. The curve is:

$$
\frac{1}{\mathrm{i}_{\mathrm{K}}^{\mathrm{P}}}=\frac{1}{1.69}+\frac{0.85}{1.69} \frac{1}{\left[\mathrm{~K}_{\mathrm{o}}\right]}+\frac{0.27}{1.69} \frac{1}{\left[\mathrm{~K}_{\mathrm{o}}\right]^{2}} .
$$

$\rho=0.994$.

Combination of $I$ with the transport system in any of its forms may be assumed to render the system inoperable in the transport process. Although combinations of the form $X I+\mathrm{K} \rightarrow X I \mathrm{~K}$ might occur, such combinations would not alter the number of units of the system in the functional form. Since the reactions will take a finite time to occur, the concentration of the transport system-inhibitor complexes at anytime, $t$, will be given by:

$$
\begin{aligned}
{[X I] } & =k_{1}{ }^{\prime}[I][X] t \\
{[X \mathrm{KI}] } & =k_{2}{ }^{\prime}[I][X \mathrm{~K}] t \\
{[X 2 \mathrm{KI}] } & =k_{3}{ }^{\prime}[I][X 2 \mathrm{~K}] t .
\end{aligned}
$$

These relations state that the concentration of any form of the transport system-inhibitor complex is

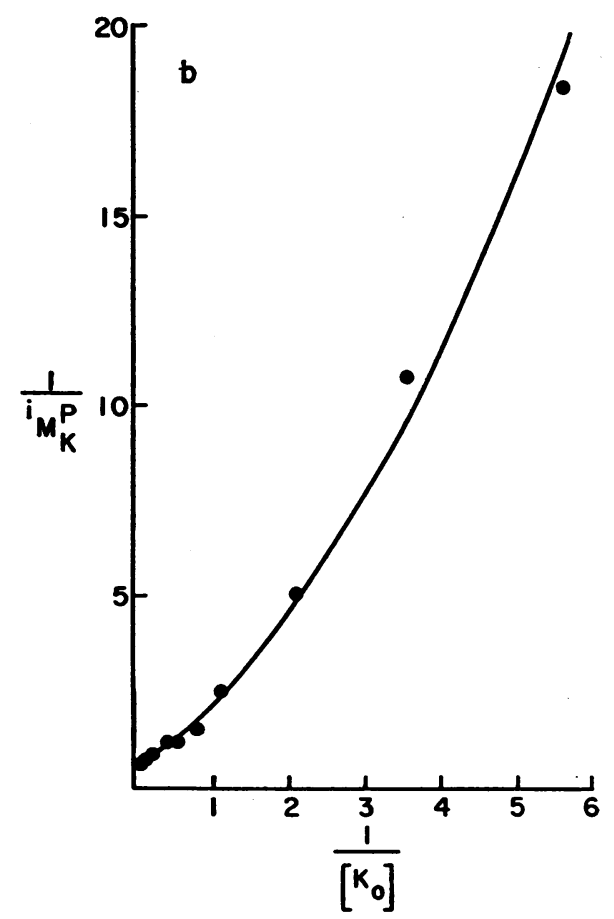

FIGURE $6 b$ MK-870, 10-8 mole/liter. The curvelis:

$$
\frac{1}{\mathrm{i}_{\mathrm{MK}} \mathrm{P}^{\mathrm{P}}}=\frac{1}{1.69}+\frac{1.98}{1.69} \frac{1}{\left[\mathrm{~K}_{\mathrm{o}}\right]}+\frac{0.66}{1.69} \frac{1}{\left[\mathrm{~K}_{\mathrm{o}}\right]^{2}} \text {. }
$$

$\rho=0.996$.

proportional to the concentration of the form of the transport system $(X, X \mathrm{~K}$, or $X 2 \mathrm{~K})$, the concentration of the inhibitor, and the time. Implicit in the formulation is the assumption that the inhibitors are reacting at a site other than the potassium-sensitive sites, i.e., that any effect of potassium on the rate of binding of the inhibitor is an allosteric one. The relative values of the rate constants $\left(k_{1}{ }^{\prime}, k_{2}{ }^{\prime}, k_{3}{ }^{\prime}\right)$ will depend on the relative affinity of the inhibitor for the unreactive transport system $(X)$, for the transport system reacted with with one potassium ion $(X \mathrm{~K})$, and for the transport system reacted with two potassium ions $(X 2 \mathrm{~K})$.

Assuming that the rate of reaction 3 is so much less than the rates of reactions 1 and 2 that reactions 1 and 2 are at equilibrium, the value of the active potassium influx at any time, $t$, in the presence of inhibitor will be :

$$
{ }^{\mathrm{i}} \mathrm{M}_{\mathbf{K}}{ }^{\mathrm{P}}=\frac{a}{\left(1+k_{3}{ }^{\prime}[I] t\right)+\frac{b}{\left[\mathrm{~K}_{\mathrm{o}}\right]}\left(1+k_{2}{ }^{\prime}[I] t\right)+\frac{c}{\left[\mathrm{~K}_{\mathrm{o}}\right]^{2}}\left(1+k_{3}{ }^{\prime}[I] t\right)},
$$


or :

$$
\frac{1}{{ }^{\mathrm{i}} \mathrm{M}_{\mathbf{K}}{ }^{\mathrm{P}}}=\frac{1}{a}\left(1+k_{3}{ }^{\prime}[I] t\right)+\frac{b}{a} \frac{1}{\left[K_{\mathrm{o}}\right]}\left(1+k_{2}{ }^{\prime}[I] t\right)+\frac{c}{a} \frac{1}{\left[K_{\mathrm{o}}\right]^{2}}\left(1+k_{3}{ }^{\prime}[I] t\right) .
$$

In order to obtain precise values for ${ }^{1} \mathrm{M}_{K}{ }^{P}$ under these circumstances, it would be necessary to determine the value of ${ }^{1} \mathbf{M}_{\mathbf{K}}{ }^{\mathbf{}}$ over the period $t-\Delta t$ to $t+\Delta t$ at very small values of $\Delta t$. Practically, it is not possible to obtain accurate values of ${ }^{1} M_{K} P$ over time periods much less than $1 \mathrm{hr}$.
Approximate values for ${ }^{1} \mathrm{M}_{\mathbf{K}}{ }^{\mathrm{P}}$ in the presence of inhibitor can be obtained by determining ${ }^{1} \mathrm{M}_{\mathbf{K}}{ }^{\mathrm{P}}$ over the time period $t=\frac{1}{2} \mathrm{hr}$ to $\mathrm{t}=1 \frac{1}{2} \mathrm{hr}$ after exposure to the inhibitor. Then, at constant extracellular concentration of inhibitor:

$$
{ }^{\mathrm{i}} \mathrm{M}_{\mathbf{K}}{ }^{\mathrm{P}}=\frac{a}{\left(1+k_{3}{ }^{\prime}[I]\right)+\frac{b}{\left[\mathrm{~K}_{\mathrm{o}}\right]}\left(1+k_{2}{ }^{\prime}[I]\right)+\frac{c}{\left[\mathrm{~K}_{\mathrm{o}}\right]^{2}}\left(1+k_{3}{ }^{\prime}[I]\right)},
$$

or:

$$
\frac{1}{{ }^{i} \mathrm{M}_{\mathbf{K}}{ }^{\mathrm{P}}}=\frac{1}{a}\left(1+k_{3}{ }^{\prime}[I]\right)+\frac{b}{a} \frac{1}{\left[\mathrm{~K}_{\mathrm{o}}\right]}\left(1+k_{2}^{\prime}[I]\right)+\frac{c}{a} \frac{1}{\left[\mathrm{~K}_{\mathrm{o}}\right]^{2}}\left(1+k_{3}{ }^{\prime}[I]\right) .
$$

Comparing equation 15 with equation 5 , it can be seen that the value of the constant term in the presence of the inhibitor will reflect the magnitude of $k_{3}{ }^{\prime}$, or the rate of reaction of $I$ with $X 2 \mathrm{~K}$; the value of the coefficient of $1 /\left[\mathrm{K}_{0}\right]$ will reflect the magnitude of $k_{2}{ }^{\prime}$, or the rate of reaction of $I$ with $X \mathrm{~K}$; and the value of the coefficient of the term in $1 /\left[\mathrm{K}_{0}\right]^{2}$ will reflect the magnitude of $k_{1}{ }^{\prime}$, or the rate of reaction of $I$ with $X$.

In the case of both strophanthidin and ethacrynic acid, the value of the constant term is unchanged; the value of the coefficient of $1 /\left[\mathrm{K}_{0}\right]$ is increased; and the value of the coefficient of $1 /\left[\mathrm{K}_{0}\right]^{2}$ is increased to a greater extent. In terms of the formulation presented above, this would correspond to the situation in which $k_{3}{ }^{\prime}$ is not increased, $k_{2}{ }^{\prime}$ is increased, and $k_{1}{ }^{\prime}$ is increased to a greater extent. This would indicate that the inhibitor reacts least rapidly with $X 2 \mathrm{~K}$, more rapidly with $X \mathrm{~K}$, and most rapidly with $X$. The effect of MK-870 was too slight at concentrations at which the drug was soluble to determine whether the same mechanism was operative in the case of this agent.

The requirement for the simultaneous presence of two potassium ions to activate the transport system is assumed in the formulation of the model presented in the theoretical section; relations derived from this model fit the observed sigmoid curve generated when the active potassium influx is plotted against the extracellular potassium concentration (1). The sigmoid character of the curve is accentuated in the presence of inhibitors. We have not, however, been able to find a model which will predict the observed curves on the basis of an inhibitor interacting competitively with a system displaying classic Michaelis-Menten kinetics; Glynn (4) has reported a similar inability to fit a curve based on such a model to the plot of the potassium influx vs. the extracellular potassium concentration in the presence of low concentrations of scillaren. In terms of the theoretical formulation, it does not appear possible to distinguish between the two potassium-sensitive sites on the basis of the kinetic behavior of the system in the presence of strophanthidin or ethacrynic acid. The results obtained seem to fit the situation in which the combination of one potassium ion with the transport system reduces the affinity of the system for the drug to some extent, and the subsequent combination of a second potassium ion further reduces the affinity of the system.

\section{ACKNOWLEDGMENT}

This work was supported by U. S. Public Health Service Research Grants 5 P01 AM-08458 and 5 R01 HE-01301 and Training grant 5 T01 AM-05054.

\section{REFERENCES}

1. Sachs, J. R., and L. G. Welt. 1967. The concentration dependence of active potassium transport in the human red blood cell. J. Clin. Invest. 46: 65 .

2. Sachs, J. R. 1967. Competitive effects of some cations on active potassium transport in the human red blood cell. J. Clin. Invest. 46: 1433.

\section{8 \\ J. R. Sachs and Louis G. Welt}


3. Schatzmann, H. J. 1953. Herzglykoside als Hemmstoffe fur den aktiven Kalium und Natriumtransport durch die Erythrocytenmembran. Helv. Physiol. Pharmacol. Acta. $11: 346$.

4. Glynn, I. M. 1957. The action of cardiac glycosides on sodium and potassium movements in human red cells. J. Physiol. (London). 136: 148.

5. Hoffman, J. F. 1966. The red cell membrane and the transport of sodium and potassium. Am. J. Med. 41: 666.

6. Cannon, P. J., R. P. Ames, and J. H. Laragh. 1963. Methylenebutyryl phenoxyacetic acid. A novel and po- tent natriuretic and diuretic agent. J. Am. Med. Assoc. 185 : 854 .

7. Hoffman, J. F., and F. M. Kregenow. 1966. The characterization of new energy-dependent cation transport processes in red blood cells. Ann. N. Y. Acad. Sci. 137: 566 .

8. Smith, E. K. M., A. Czerwinski, and L. G. Welt. 1967. A dissociation between erythrocyte Pump II and membrane ATPase. Clin. Res. 15: 372.

9. Welt, L. G., J. R. Sachs, and T. J. McManus. 1964. An ion transport defect in erythrocytes from uremic patients. Trans. Assoc. Am. Physicians. 77: 169. 